\title{
Systematic Studies on the Breakdown of p,p'-DDT in Tobacco Smokes*
}

\author{
by N. M. Chopra**, John J. Domanski, and Neil B. Osborre \\ Department of Chemistry, North Carolina Agricultural and Technical State University, \\ Greensboro, N. C., USA
}

Recently there has been much controversy concerning the use of DDT as a pesticide. This has resulted in partial or total ban on it in several countries. In this country DDT is being phased out over a period of two years (I). In 1968 DDT was removed from recommended compounds for tobacco (3).

Inspite of the removal of DDT as a pesticide for tobacco our studies are important for two reasons: First, tobacco leaf is cured and mellowed before its use in the manufacture of cigarettes. This usually takes about two or three years and causes the possibility of carryover of DDT on cigarettes for several years. Second, the studies throw light on the mechanisms of the reactions involved in the degradation of pesticides in tobacco smokes.

This paper is divided into two sections: Section I deals with the isolation and identification of the degradation products from the pyrolysis of $\mathrm{p}, \mathrm{p}^{\prime}$-DDT in a nitrogen atmosphere. Section 2 deals with the pyrolytic degradation of $p, p^{\prime}-D D T$ intimately mixed with tobacco.

\section{SECTION 1}

\section{Pyrolysis of p,p'-DDT In a Nitrogen Atmosphere}

Very little work has been reported on the pyrolysis of DDT. Cavenah and Johns (7) have studied pyrolysis of DDT, but this was in conjunction with their method of identifying DDT by its "pyrolysis spectra". Recently, Mosier, Guenzi, and Miller (15) have proposed a free radical mechanism for photodecomposition of DDT. Some of their mechanisms are similar to those reported herein although reaction conditions were very different.

\footnotetext{
* Presented as two papers entitled: "Isolation and Identification of the Degradation Products from the Pyrolysis of $p, p^{2}-D D T$ in a Nitrogen Atmosphere" and "Degradation of p,p'-DDT in Tobacco Smokes" before the 23rd Tobacco Chemists" Research Conference at Philadelphia, October 1969.

Detailed description of the methods to be published at a later date.

4* Author to whom correspondence should be addressed.
}

\section{EXPERIMENTAL AND RESULTS}

The pyrolysis of p,p'-DDT $(99.9 \%+$ pure) was conducted in a nitrogen atmosphere in a quartz tube at $900^{\circ} \mathrm{C}$. The temperature was selected because it corresponded to the burning zone of cigarette (23). The pyrolyzed products were collected in $-80^{\circ} \mathrm{C}$ traps containing pentane.

The pentane solutions from the traps were combined and refluxed to remove any methyl chloride present. No methyl chloride was detected in the gases evolved: The pentane solution, stripped from highly volatile constituents, was then washed with water to remove $\mathrm{HCl}$, dried, and distilled. The distillate, called PED (pentane extract distillate), was found to contain dichloromethane, chloroform, carbon tetrachloride, trichloroethylene, tetrachloroethylene, chlorobenzene, and hexachloroethane when chromatographed on a GLC $3 \%$ SE 30 column (see Figure 1).

These compounds were isolated by fractional distillation, chromatography on activated alumina, and identified by cochromatography with authentic samples on: [1] a $6 \mathrm{ft} 3 \%$ SE 30 column, [2] a $6 \mathrm{ft} 20 \%$ carbowax $20 \mathrm{M}$ column, and [3] a $6 \mathrm{ft} 5 \%$ SE 30 column. Both electron capture and microcoulometric detectors were used. Also, hexachloroethane was identified by its infrared spectrum, and other compounds by various colorimetric tests (8).

The residue following distillation of PED was called NVF (non volatile fraction). When chromatographed on a $3 \%$ SE 30 column, NVF was found to contain hexachloroethane, $\alpha, p$-dichlorotoluene, $\mathrm{p}, \mathrm{p}^{\prime}$-dichlorobiphenyl, bis-(p-chlorophenyl)methane, 'cis-p,p'-dichlorostilbene, bis-(p-chlorophenyl)chloromethane, $p, p^{\prime}-D D M, p, p^{\prime}-$ DDE and trans-p,p'-dichlorostilbene, $p, p^{\prime}-T D E$, and p,p'-DDT (see Figure 2). These compounds were isolated by repeated chromatography on Florisil columns, and identified by cochromatography with authentic samples on a $6 \mathrm{ft} 3 \% \mathrm{SE} 30$ column and, with the exception of dichlorostilbenes, by their infrared spectra. 
Figure 1 Pyrolysis of P,p'-DDT in a nitrogen atmosphere: GLC chrom atogram of the PED traction

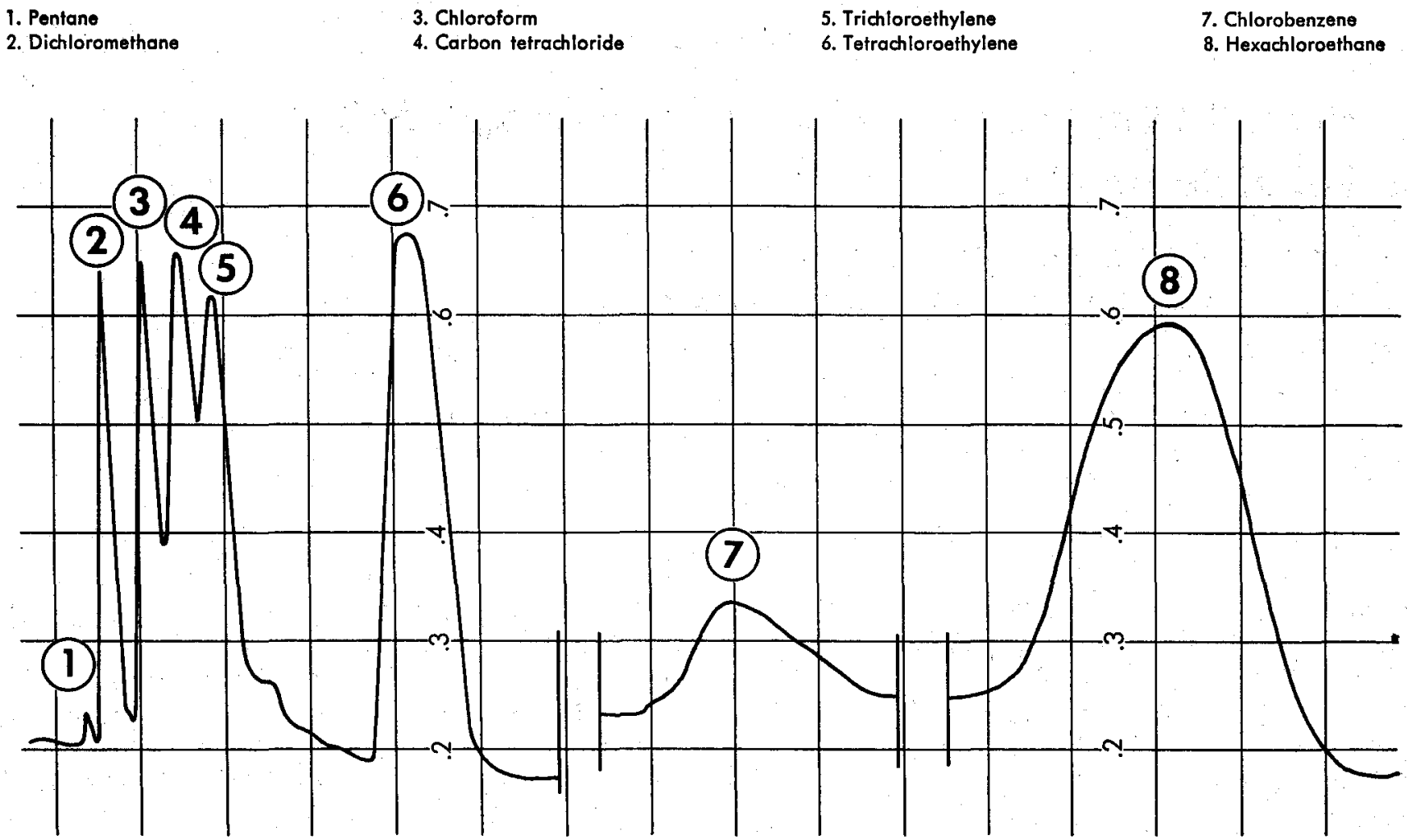

Figure 2 Pyrolysis of P,P'-DDT in a nitrogen atmosphere: GLC chromatogram of the NVF

1. Pentane

2. Hexachloroethane

3. $\alpha, p$-Dichlorotolvene

4. p,p'-Didhlorobiphenyl
5. Bis-(p-chlorophenyl)methane

6. Cis-p,p'-dichlorostilbene

7. Bis-(p-chlorophenyl)chloromethane

8. $p, p^{\prime}-D D M$
9. $p, p^{\prime}-D D E$ and trans-p,p'-didhlorostilbene 10. $p, p^{\prime}-$ TDE

11. $p, p^{\prime}$-DDT

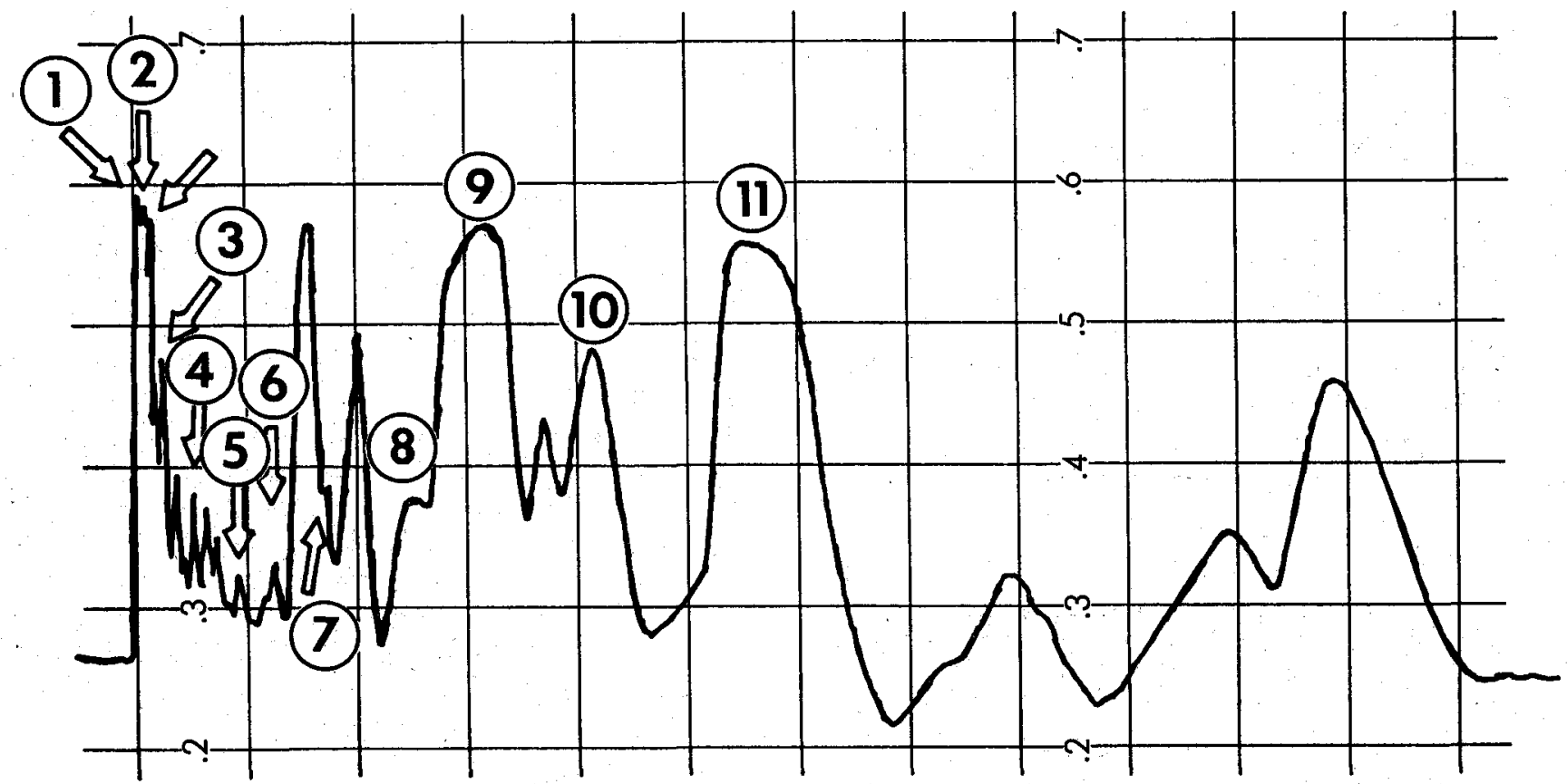




\section{DISCUSSION}

Three reaction mechanisms are proposed which could explain the formation of the compounds formed during the pyrolysis of DDT. They are:

1. Mechanisms involving dehydrochlorination and hydrogenation reactions

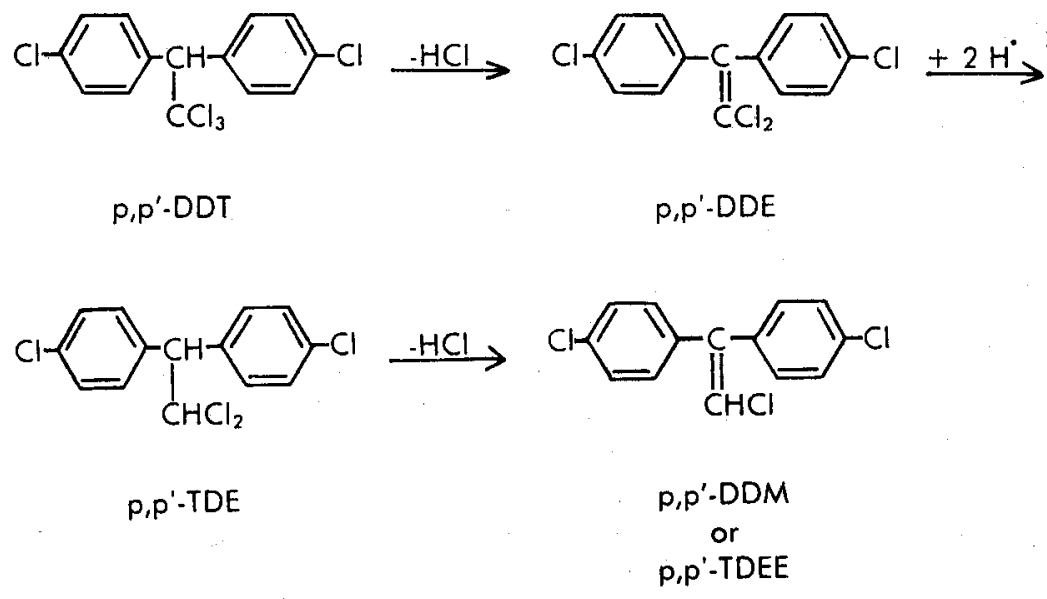

2. Mechanisms involving the fragmentation of $D D T$ molecule

There are two types of fragmentation reactions: fragmentations involving the formation of (i) free radicals, and (ii) carbenes.

(i) Fragmentations involving the formation of free radicals:

a.
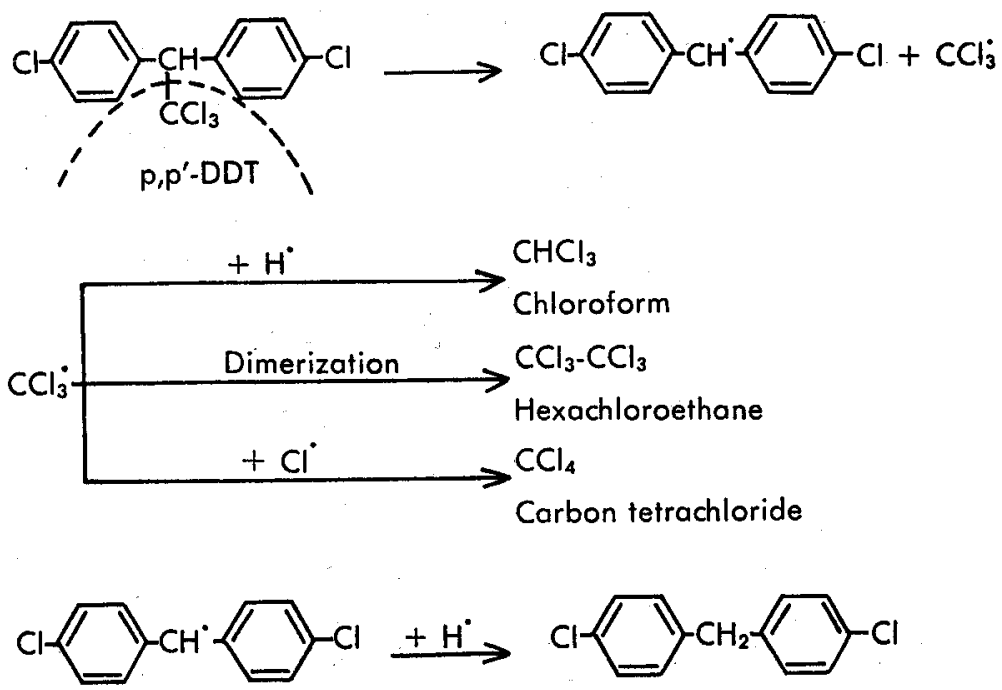

Bis-(p-chlorophenyl)methane

b.
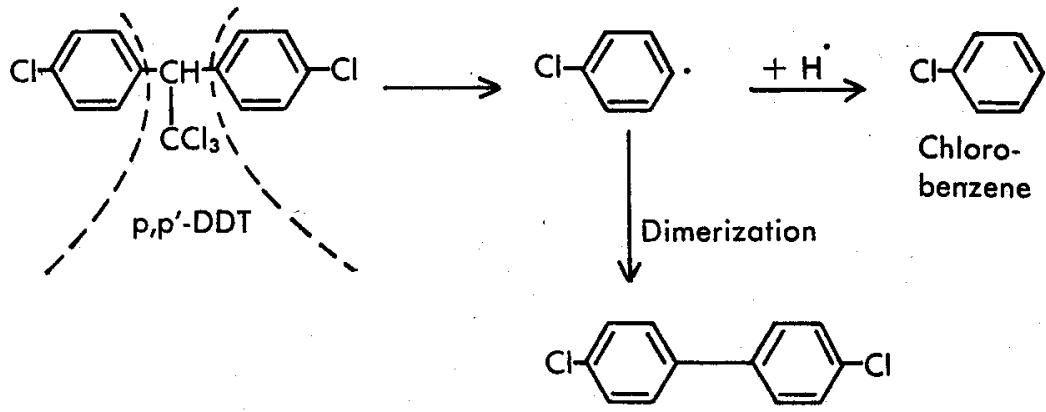

$p, p^{\prime}$-Dichlorobiphenyl 
(ii) Fragmentations involving the formation of carbenes:

a.<smiles>Clc1ccc(C2CCCC2CC2(c3ccc(Cl)cc3)CCCC2)cc1</smiles>

$P, p^{\prime}-D D T$

b.

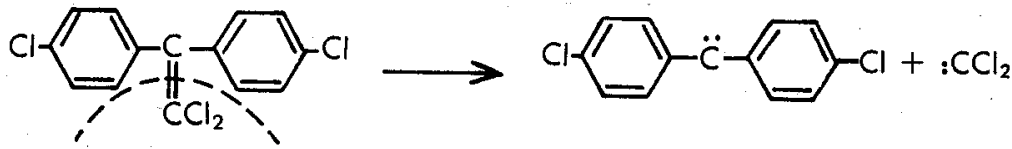

$p, p^{\prime}-D D E$

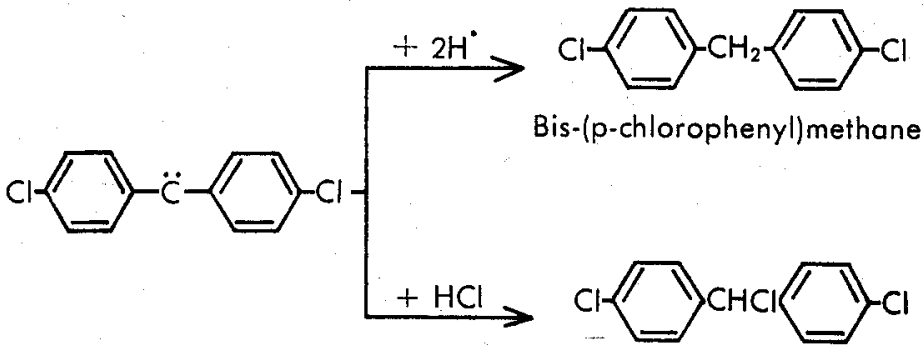

Bis-(p-chlorophenyl)chloromethane

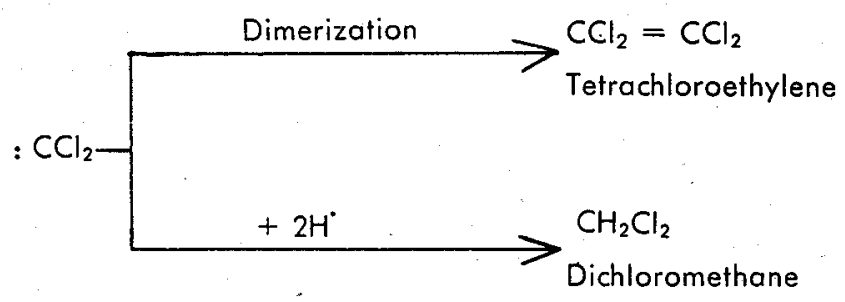

c.<smiles>CC(C)(c1ccc(Cl)cc1)C(C)(C)c1ccc(Cl)cc1</smiles>

$\longrightarrow \quad: \mathrm{C}=\mathrm{CCl}_{2} \stackrel{\mathrm{HCl}}{\longrightarrow} \mathrm{CHCl}=\mathrm{CCl}_{2}$

Trichloroethylene

The chlorophenyl radical could dimerize to give p,p'-dichlorobiphenyl or chlorobenzene as mentioned above in mechanism (i) b.

3. Mechanisms involving rearrangement reactions

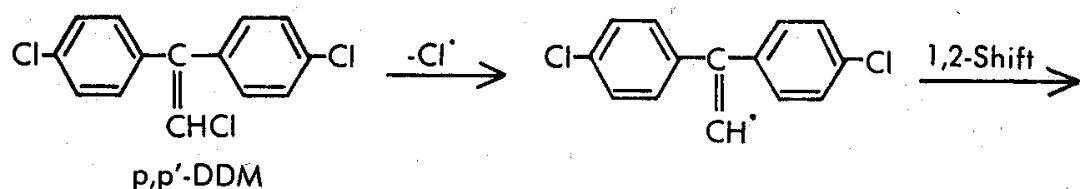<smiles>Clc1ccc(C=Cc2ccc(Cl)cc2)cc1</smiles><smiles>CCCCCCCCCC=[C]c1ccc(Cl)cc1</smiles>

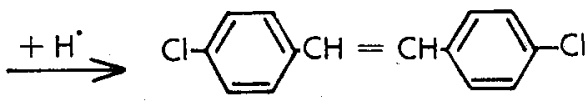

Cis- and trans-dichlorostilbenes

In this study it should be remembered that when DDT is pyrolysed in an atmosphere of nitrogen, the concen- tration of DDT is high, and that of hydrogen is low since it can come only from DDT itself; whereas, when 
DDT treated tobacco is smoked then the concentration of DDT is low while that of hydrogen is high (16). Thus, during the smoking of DDT-treated tobacco these factors preclude the formation of dimers and polymers, and hydrochlorides of the DDT pyrolysis products. Other degradation products whose formation involve hydrogenation, fragmentation and rearrangement may not be retarded. The next section will indicate to what extent this prediction is correct.

\section{SECTION 2}

\section{Degradation of p,p'-DDT in Tobacco Smokes}

It is rather surprising that even though several systematic attempts have been made to study the metabolism and degradation of DDT in various test animals $(4,19$, $21)$, soil $(10,13)$, insects $(18,24)$, and plants (11), no systematic attempt has till now been made to study the breakdown of DDT in tobacco and cigarette smokes. It is true that DDT, DDE, TDE, DDM, and cis- and trans-dichlorostilbenes have been found in cigarette smokes $(5,6,12,14)$, but it is also true that DDT, DDE, TDE and even DDM have been found on intact cigarettes $(5,12,22)$. Thus, the presence of these compounds in cigarette smokes, as reported so far, does not shed much light on the breakdown of DDT in cigarette and tobacco smoke. It is possible that attempts at the systematic study of the breakdown of DDT in cigarette smokes were made, but the intractable nature of tobacco smokes, and the erroneous belief that all organochlorine compounds are extremely sensitive to electron capture detectors may have made such efforts of no avail. It may be mentioned that aryl halides, such as chlorobenzene, bis-(p-chlorophenyl)methane etc., and compounds in which n-electrons of halogens are involved in resonance, such as, vinyl chloride, have a poor response towards electron capture detectors $(2,9)$.

Another surprise is that almost all workers so far have ignored looking into the volatile fractions of the smokes from cigarettes or tobacco containing DDT or TDE. It is true that Newsome et al. (17), and Philippe and Hobbs (20) have found methyl chloride in volatile gases of cigarette smokes, but as far as our information goes, the formation of methyl chloride has not been linked to any precursor.

\section{EXPERIMENTAL AND RESULTS}

$200 \mathrm{~g}$ of tobacco fortified with $200 \mathrm{ppm}$ of $\mathrm{p}, \mathrm{p}^{\prime}$-DDT $(99.9 \%+$ pure) was smoked in a porcelain funnel, and the resultant smoke passed through $-80^{\circ} \mathrm{C}$ traps containing pentane. The pyrolysed products were worked up as reported in Section 1. Methyl chloride was detected in the gases given off when the pentane extract of tobacco smoke was refluxed. Its presence was confirmed by cochromatography with authentic samples on OV-17 and $3 \%$ SE 30 GLC columns, with electron capture and microcoulometric detectors. Smoke from untreated tobacco was also examined for methyl chloride but it was not detected.

The pentane extract, after the removal of methyl chloride, was heated on a water bath. The distillate was

Figure 3 Pyrolysis of P,P'-DDT in P,P'-DDT-treated tobacco smokes: GLC chromatogram of the NVF with electron capture delector

1. Bis-(p-chlorophenyl)methane 2. p,p'-Dichlorobenzophenone
3. Unknown
4. p,p'-DDM
5. Trans-p,p'-dichlorostilbene 6. $p, p^{\prime}-D D E$
7. $p, p^{\prime}-$ TDE

8. $p, p^{\prime}$-DDT

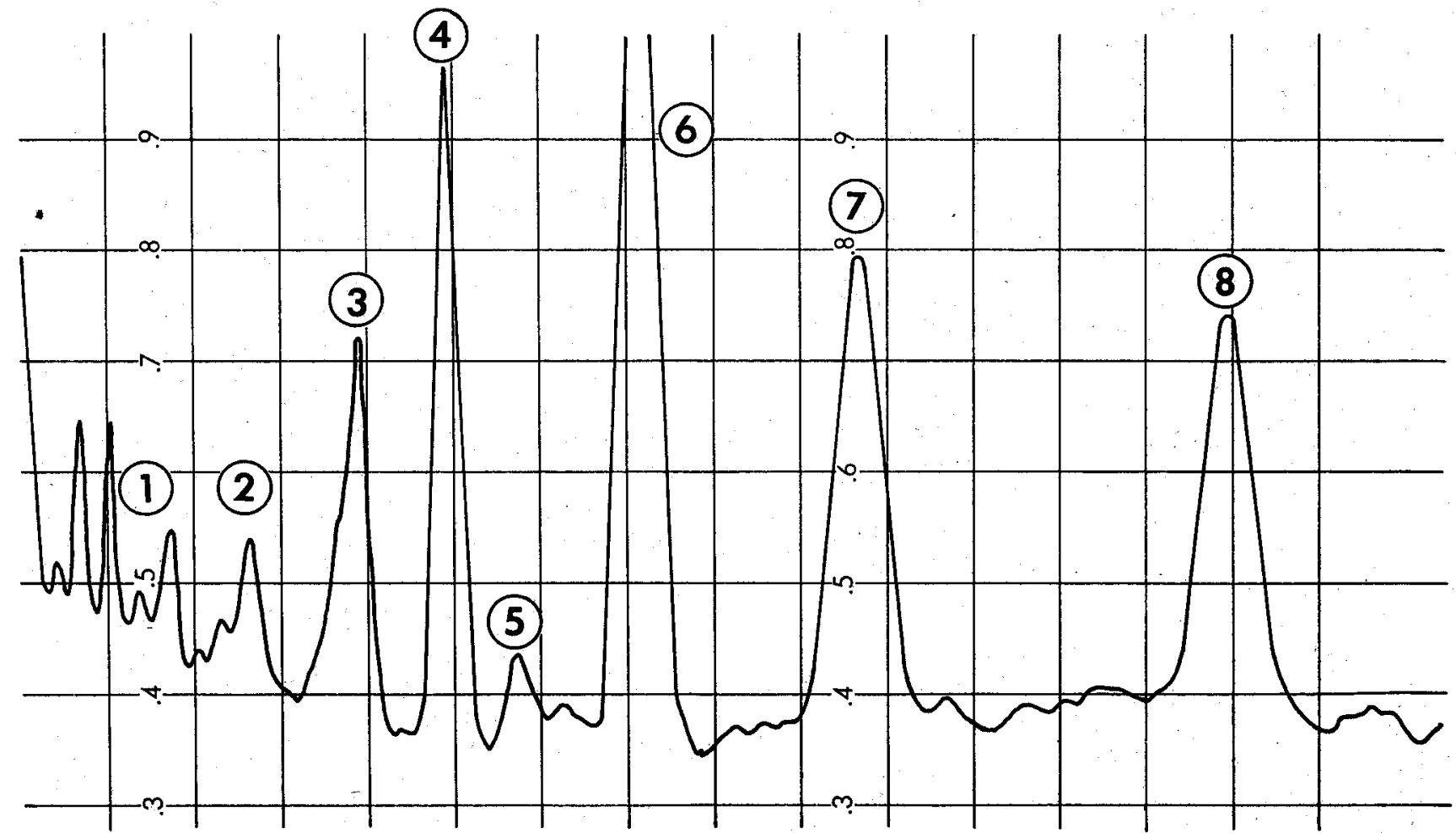


Figure 4 Pyrolysis of P,p'-DDT in P,p'-DDT-Ireated tobacco smokes: GLC chromatogram of the NVF with microcoulometric detector

1. Bis-(p-chlorophenyl)methane

2. Unknown

3. p,p'-Dichlorobenzophenone
4. Unknown

5. $p, p^{\prime}-D D M$

6. Trans-p, $p^{\prime}$-dichlorostilbene
7. $p, p^{\prime}-D D E$

8. $p, p^{\prime}-T D E$

9. $p, p^{\prime}-D D T$

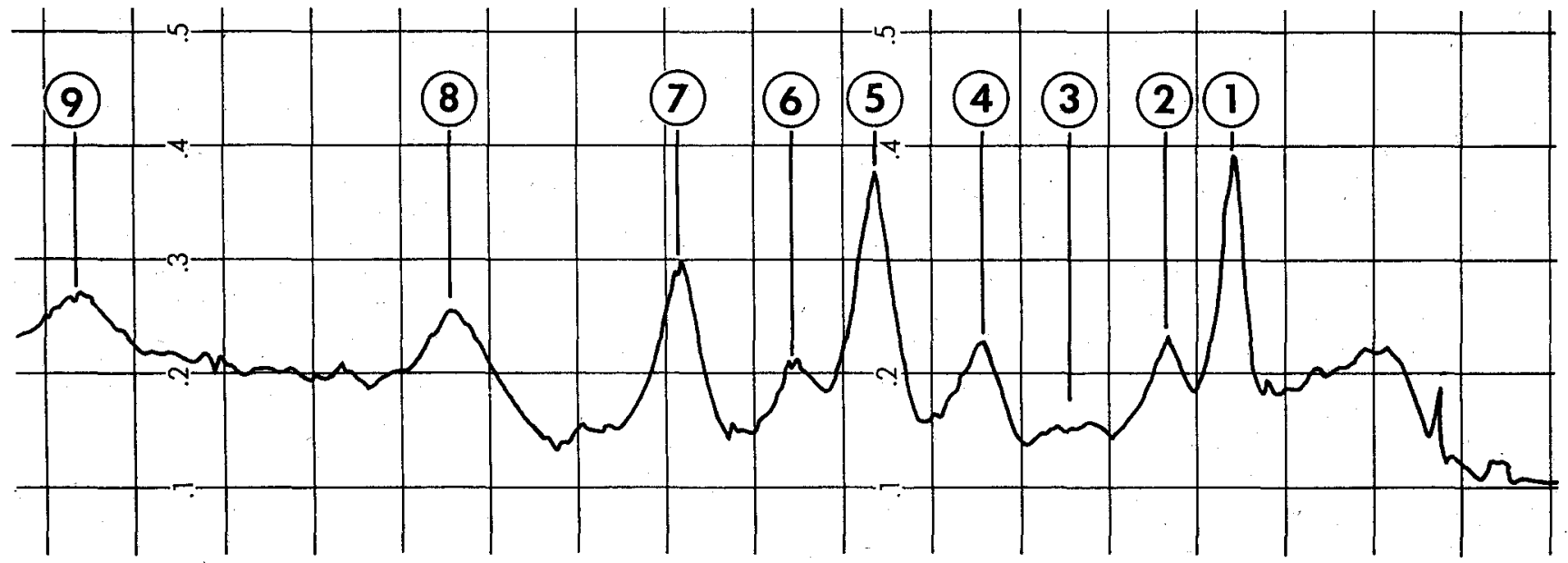

collected and will be reported at a later date. The residue was worked up by a modification of the method due to Hoffmann and Rathkamp (12). The fraction containing haloger compounds, called NVF (non volatile fraction), was chromatographed on a $6 \mathrm{ft} 3 \% \mathrm{SE}$ 30 column. Chromatograms obtained with electron capture and microcoulometric detectors are shown in Figures 3 and 4 respectively.

Figure 3 shows the presence of bis-(p-chlorophenyl)methane, $p, p^{\prime}$-dichlorobenzophenone, unknown, $\mathrm{p}, \mathrm{p}^{\prime}$ DDM, trans-p, $\mathrm{p}^{\prime}$-dichlorostilbene, $\mathrm{p}, \mathrm{p}^{\prime}-\mathrm{DDE}, \mathrm{p}, \mathrm{p}^{\prime}-\mathrm{TDE}$, and $p, p^{\prime}-D D T$. It may be noticed that the peak due to bis-(p-chlorophenyl)methane is a small peak in Figure 3 and one of the biggest peaks in Figure 4. Incidentally, Figure 3 is in good agreement with the chromatogram obtained by Hoffmann and Rathkamp (12). Substances present in the NVF were isolated by repeated chromatography on deactivated alumina and identified by cochromatography with authentic samples on $3 \%$ SE 30 , and OV-17 GLC columns with electron capture and microcoulometric detectors.

An attempt was also made to estimate some chlorohydrocarbons present in the NVF. The results (Table 1 ) are not quantitative because not all of the tobacco pyrolysate was collected. However, it is significant that bis-(p-chlorophenyl)methane and p,p'-DDM

Table 1 Amount of various p,p'-DDT degradation products present in P,P'-DDT-treated tobacco smokes

\section{Compound}

Amount recovered per gram of tobacco smoked

$\begin{array}{ll}\text { p,p'-DDT } & 2.4 \mu \mathrm{g} \\ \text { p,p'-DDE } & 3.3 \mu \mathrm{g} \\ \text { p,p'-TDE } & 1.8 \mu \mathrm{g} \\ \text { p,p'-DDM } & 4.4 \mu \mathrm{g} \\ \text { Trans-p,p'-dichlorostilbene } & 1.5 \mu \mathrm{g} \\ \text { Bis-(p-chlorophenyl)methane* } & 4.3 \mu \mathrm{g} \\ \text { p,p'-Dichlorobenzophenone } & 0.9 \mu \mathrm{g}\end{array}$

- Determined on the microcoulometric delector. are present in large amounts. Also, the amount of p, 'p'dichlorobenzophenone is about one-fifth of the amount of bis-(p-chlorophenyl)methane produced.

One important constituent of the degradation product of DDT, not shown in Table 1 , is $\mathrm{HCl}$. This compound was not estimated since it can only be estimated by the $\mathrm{H}^{+}$or $\mathrm{Cl}^{-}$it produces, and these ions are very seriously interfered with by other constituents of tobacco smokes. Of course, there are other chlorohydrocarbons present in volatile fractions which are also not reported in Table $x$. In total evaluation of the degradation of DDT, these should also be considered.

\section{CONCLUSIONS}

1. The formation of all the degradation products of DDT in tobacco smokes are consistent with the prediction which could be made on the basis of the study of pyrolysis of DDT in nitrogen.

2. The DDT pyrolysis products in the non-volatile fraction of tobacco smokes, with the exception of dichlorostilbenes, are the same as the DDT metabolic products found in living organisms $(4,19,21)$, but the mechanisms of their formation are different.

3. Volatile products formed on the pyrolysis of DDT in tobacco smokes, such as methyl chloride, are not formed in the metabolism and degradation of DDT in test animals, soil, plants, and insects.

4. Methyl chloride is not a constituent of the natural (untreated) tobacco smokes. It probably comes from the chlorohydrocarbon applications to tobacco plant, or tobacco in storage, or from reconstituted tobacco.

5. The formation of TDE, bis-(p-chlorophenyl)methane, methyl chloride, and dichlorostilbenes indicate that hydrogenation is one of the most important reactions taking place in the smoking of tobacco, presumably in the burning zone itself where large amount of hydrogen is available (16).

6. The formation of methyl chloride, bis-(p-chlorophenyl)methane, and $p, p^{\prime}$-dichlorobenzophenone in- 
dicate that some carbenes, such as dichlorocarbene and bis-(p-chlorophenyl)carbene, are formed during the pyrolysis of DDT. Dichlorocarbene and bis-(pchlorophenyl)carbene can pick up hydrogen to give methyl chloride and bis-(p-chlorophenyl)methane respectively; also bis-(p-chlorophenyl)carbene can pick up an oxygen atom and produce $p, p^{\prime}$-dichlorobenzophenone.

7. The small amount in which dichlorobenzophenone is produced as compared to bis-( $\mathrm{p}$-chlorophenyl)methane may be due to that, some of the bis-(p-chlorophenyl)carbene escaped hydrogenation (because of its great stability due to a $n-\Pi-n-\Pi-n$ resonance system), and later on picked up an oxygen atom from air to give $p, p^{\prime}$-dichlorobenzophenone.

8. The formation of dichlorocarbene and trichloromethyl radicals suggests that these are some of the "primary alkylating" agents in tobacco smoke, and that methyl chloride is really a "secondary alkylating" agent.

\section{SUMMARY}

These studies, on the pyrolysis of DDT, can be divided into two sections. Section I deals with the pyrolysis of $\mathrm{p}, \mathrm{p}^{\prime}$-DDT in a nitrogen atmosphere at $900^{\circ} \mathrm{C}$ and subsequent isolation and identification of $\mathrm{CH}_{2} \mathrm{Cl}_{2}, \mathrm{CHCl}_{3}$, $\mathrm{CCl}_{4}, \mathrm{CHCl}=\mathrm{CCl}_{2}, \mathrm{CCl}_{2}=\mathrm{CCl}_{2}$, chlorobenzene, $\mathrm{CCl}_{3-}$ $\mathrm{CCl}_{3}, \alpha, p$-dichlorotoluene, $\mathrm{p}, \mathrm{p}$-dichlorobiphenyl, bis-(pchlorophenyl)methane, cis-p, $\mathrm{p}^{\prime}$-dichlorostilbene, bis-( $\mathrm{p}$ chlorophenyl)chloromethane, $\mathrm{p}, \mathrm{p}^{\prime}-\mathrm{DDM}, \mathrm{p}, \mathrm{p}^{\prime}-\mathrm{DDE}$, trans-p, $\mathrm{p}^{\prime}$-dichlorostilbene, $\mathrm{p}, \mathrm{p}^{\prime}-\mathrm{TDE}$, and $\mathrm{p}, \mathrm{p}^{\prime}-\mathrm{DDT}$. Mechanisms for the formation of these compounds are proposed, and on that basis prediction is made on the formation of DDT degradation products when DDTtreated tobacco is smoked. Section 2 deals with pyrolytic degradation of DDT incorporated in tobacco. Methyl chloride, bis-(p-chlorophenyl)methane, $\mathrm{p}, \mathrm{p}^{\prime}$ dichlorobenzophenone, $p, p^{\prime}-D D M$, trans- $p, p^{\prime}$-dichlorostilbene, $p, p^{\prime}-D D E, p, p^{\prime}-T D E$ and $p, p^{\prime}-D D T$ were identified as the pyrolysis products. Based on the type and nature of pyrolysis products obtained, eight conclusions are made.

\section{ZUSAMMENFASSUNG}

Die vorliegenden Untersuchungen über die Pyrolyse von DDT können in zwei Abschnitte geteilt werden. In Teil 1 werden die Pyrolyse von $p, p^{\prime}$-DDT in Stickstoffatmosphäre bei $900^{\circ} \mathrm{C}$ und die nachfolgende Isolierung und Identifizierung von $\mathrm{CH}_{2} \mathrm{Cl}_{2}, \mathrm{CHCl}_{3}, \mathrm{CCL}_{4}, \mathrm{CHCL}=$ $\mathrm{CCL}_{2}, \mathrm{CCl}_{2}=\mathrm{CCL}_{2}, \quad$ Chlorbenzol, $\mathrm{CCl}_{3}-\mathrm{CCl}_{3}, 2,4^{-}$ Dichlortoluol, $\mathrm{p}, \mathrm{p}^{\prime}$-Dichlordiphenyl, bis-(p-Chlorphenyl)methan, cis-p,p'-Dichlorstilben, bis-(p-Chlorphenyl)chlormethan, $\mathrm{p}, \mathrm{p}^{\prime}-\mathrm{DDM}, \mathrm{p}, \mathrm{p}^{\prime}-\mathrm{DDE}$, trans-p,p'-Dichlorstilben, $p, p^{\prime}-T D E$ und $p, p^{\prime}-D D T$ beschrieben. Für die Bildung dieser Verbindungen werden Mechanismen vorgeschlagen. Auf der Basis dieser Mechanismen werden Voraussagen über die Entstehung von Abbauprodukten von DDT beim Rauchen von mit DDT behandeltem
Tabak gemacht. In Teil 2 wird der pyrolytische Abbau des im Tabak enthaltenen DDT behandelt. Methylchlorid, bis-( $p$-Chlorphenyl)methan, p, $\mathrm{p}^{\prime}$-Dichlorbenzophenon, $p, p^{\prime}-D D M$, trans- $p, p^{\prime}-$ Dichlorstilben, $p, p^{\prime}-D D E$, $p, p^{\prime}-T D E$ und $p, p^{\prime}-D D T$ wurden als Pyrolyseprodukte identifiziert. Auf der Grundlage der Art und der Eigenschaften der erhaltenen Pyrolyseprodukte werden acht Schlußfolgerungen gezogen.

\section{RÉSUMÉ}

Nous pouvons diviser ces études, concernant la pyrolyse de DDT, en deux sections. La première section relate la pyrolyse de $\mathrm{p}, \mathrm{p}^{\prime}-\mathrm{DDT}$ en atmosphère azotée à $900^{\circ} \mathrm{C}$, et ensuite la séparation et l'identification de $\mathrm{CH}_{2} \mathrm{Cl}_{2}, \mathrm{CHCl}_{3}, \mathrm{CCl}_{4}, \mathrm{CHCl}=\mathrm{CCl}_{2}, \mathrm{CCl}_{2}=\mathrm{CCl}_{2}$, chlorobenzène, $\mathrm{CCl}_{3}-\mathrm{CCl}_{3}, \alpha, p$-dichlorotoluène, $\mathrm{p}, \mathrm{p}^{\prime}$-dichlorobiphényl, bis-(p-chlorophényl)méthane, cis-p,p'dichlorostilbène, bis-( $\mathrm{p}$-chlorophényl)chlorométhane, $p, p^{\prime}-D D M, p, p^{\prime}-D D E$, trans-p, $p^{\prime}$-dichlorostilbène, $p, p^{\prime}-$ $T D E$, et $p, p^{\prime}-D D T$. Nouis proposons des mécanismes de formation de ces composés, et nous basant là-dessus, nous prédisons la formation de produits de dégradation du DDT lorsqu'on fume du tabac traité au DDT. La zème section traite de la dégradation pyrolytique du DDT incorporé au tabac. Les produits de pyrolyse identifiés sont les suivants: méthylchloride, bis-(p-chlorophényl)méthane, $p, p^{\prime}$-dichlorobenzophénone, $p, p^{\prime}-$ $D D M$, trans-p, $p^{\prime}$-dichlorostilbène, $p, p^{\prime}-D D E, p, p^{\prime}-T D E$ et $p, p^{\prime}-D D T$. Nous basant sur le type et la nature des produits pyrolysés obtenus, nous tirons huit conclusions.

\section{REFERENCES}

1. Anonymous: Chem. Eng. News, November 17, 1969, p. 11.

2. Anonymous: Gas Chromatography, General Course. Hewlett-Packard, F\& M Scientific Division, Palo Alto, California, p. 1-4-12.

3. Anonymous: 22nd Tobacco Workers' Conference, Ashville, N.C., July 22-24, 1968.

4. Bailey, S. P., Bunyan, P. J., Rennison, B. D., Taylor, A.: Toxicol. Appl. Pharmacol. 14 (1969) 13.

5. Bowery, T. G., Evans, W. R., Guthrie, F. E., and Rabb, R. L.: J. Agric. Food Chem. 7 (1959) 693.

6. Bowery, T. G., Gatterdam, P. E., Guthrie, F. E., and Rabb, R. L.: J. Agric. Food Chem. 13 (1965) 356.

7. Cavenah, R. C., and Johns, T.: Analyzer. Publ. Scientific and Process Instruments Division, Beckman Instrument Inc., Fullerton, California, 7 (1966) 3.

8. Chopra, N. M., Domanski, J. J., and Osborne, N. B.: Unpublished results.

9. Chopra, N. M., Domanski, J. J., and Sherman, L. R.: Unpublished results.

10. Guenzi, W. D., and Beard, W. E.: Science 156 (1967) 1116. 
11. Harrison, R. B., Holmes, D. C., Roburn, J., and Tatton, J. O'G.: J. Sci. Food Agric. 18 (1967) 10.

12. Hoffmann, D., and Rathkamp, G.: Beitr. Tabakforsch. 4 (1968) 201.

13. Ko, W. H., and Lockwood, J. L. : Can. J. Microbiol. 14 (1968) 1069.

14. Mold, J. D., and Walker, T. B.: Tob. Sci. I (1957) 161.

15. Mosier, A. R., Guenzi, W. D., and Miller, L. L.. Science 164 (1969) 1083.

16. Newsome, J. R., and Keith, C. H.: Tob. Sci. 9 (1965) 65.

17. Newsome, J. R., Norman, V., and Keith, C. H.: Tob. Sci. 9 (1965) 102.

18. Perry, A. S., Hennessy, D. J., and Miles, J. W.: J. Econ. Entomol. 60 (1967) 568.

19. Peterson, J. E., and Robinson, W. H.: Toxicbl. Appl. Pharmacol. 6 (1964) 321.

20. Philippe, R. J., and Hobbs, M. E.: Anal. Chem. 28 (1956) 2002.

21. Pinto, J. D., Camien, M. N., and Dunn, M. S.: J. Biol. Chem. 240 (1965) 2148.
22. Sheets, T. J., Smith, J. W., and Jackson, M. D.: Tob. Sci. 12 (1968) 66.

23. Touey, G. P., and Mumpower, R. C.: Tob. Sci. 1 (1957) 33.

24. Witt, J. M.: Diss. Abs. 26 B (1966) 7020.

\section{Acknowledgements}

The authors wish to thank the Council for Tobacco Research-USA for the Research Grant which has made these investigations possible; Drs. Frank E. Guthrie and T. J. Sheets of the North Carolina State University, Raleigh, for a gift of pesticide free tobacco; and Dr. B. R. Ray and Mr. Allan E. Foote for work they did at the early stages of research mentioned in Section 1.

The authors' address:

North Carolina Agricultural and Technical State University, Department of Chemistry, Greensboro, Noxth Carolina, 27411, USA 